This is the peer reviewed version of the following article:

Ponti M, Turicchia E, Ferro F, Cerrano C, Abbiati M. The understorey of gorgonian forests in mesophotic temperate reefs. Aquatic Conserv: Mar Freshw Ecosyst. 2018;28:1153-1166.

which has been published in final form at:

https://doi.org/10.1002/aqc.2928

(C) 2018 John Wiley \& Sons, Ltd. This article may be used for non-commercial purposes in accordance with Wiley Terms and Conditions for Use of Self-Archived Versions.

(https://authorservices.wiley.com/author-resources/Journal-Authors/licensing/self-archiving.html) 


\section{The understorey of gorgonian forests in mesophotic temperate reefs}

2

3 Massimo Ponti $^{1,3, *}$, Eva Turicchia ${ }^{1,3}$, Francesca Ferro ${ }^{1}$, Carlo Cerrano ${ }^{2,3}$, Marco Abbiati ${ }^{1,3,4}$

4

5

$6 \quad{ }^{1}$ Dipartimento di Scienze Biologiche, Geologiche e Ambientali (BiGeA) \& Centro

7 Interdipartimentale di Ricerca per le Scienze Ambientali (CIRSA), University of Bologna,

$8 \quad$ Via S. Alberto 163, 48123 Ravenna, Italy.

$9 \quad{ }^{2}$ Dipartimento di Scienze della Vita e dell'Ambiente (DiSVA), Polytechnic University of

10 Marche, Via Brecce Bianche, 60131 Ancona, Italy.

$11{ }^{3}$ Consorzio Nazionale Interuniversitario per le Scienze del Mare (CoNISMa), Piazzale

12 Flaminio 9, 00196 Roma, Italy.

$13{ }^{4}$ Istituto di Scienze Marine (ISMAR), Consiglio Nazionale delle Ricerche, Bologna, Italy.

14

15

16

$17 *$ Corresponding author: Massimo Ponti, Laboratori di Scienze Ambientali, Università di Bologna, Via S.

18 Alberto 163, I-48123 Ravenna, Italy. Phone: +39 0544 937400. E-mail: massimo.ponti@unibo.it 


\section{Abstract}

21 1. In the Mediterranean Sea, dense populations of the gorgonian Paramuricea clavata shape marine animal forests characterizing the seascapes of coralligenous habitats. Despite the concerns for its health, due to several anthropogenic threats and recent mass mortality events mainly triggered by thermal anomalies, the understorey of its forests and the ecological processes they promote are still little known. Here, the abundance and composition of epibenthic assemblages inside and outside $P$. clavata forests were investigated across the central and western Mediterranean Sea, by applying a multifactorial sampling design.

2. In spite of the large variability in the structures of epibenthic assemblages at local and regional scales, the gorgonian understoreys share some common features, such as higher abundances of calcareous builder organisms and a reduced invasion by the nonindigenous alga Caulerpa cylindracea, compared to the adjacent unforested rocky

4. Conservation strategies should reduce the risk of mechanical damage by regulating fishing activities, anchorages and scuba diving where gorgonian forests are present. Moreover, 

recover gorgonian forests integrity.

46

47 Keywords: alien species, benthos, biodiversity, climate change, endangered species,

48 invertebrates, subtidal 
50 In many marine habitats erect organisms may form dense populations resembling small terrestrial forests. They include canopy-forming algae (e.g. kelps, fucoids), but also branched sessile invertebrates (e.g. sponges, cnidarians, bryozoans) able to form dense mono- or plurispecific "animal forests” (sensu Rossi, Bramanti, Gori, \& Orejas Saco del Valle, 2017). Forests forming species directly or indirectly affect availability of abiotic and biotic resources by structural changes and therefore may be considered ecosystem engineers (Jones, Lawton, \& Shachak, 1994; reviewed in Romero, Gonçalves-Souza, Vieira, \& Koricheva, 2015). Terrestrial forest trees control the understorey by providing favourable microclimates, with less fluctuations of environmental variables (e.g. humidity, temperature, organic matter, nutrient, shading) compared to habitats outside tree assemblages, and by driving interactions among animals and plants (Wright, 2002). In the marine environment, kelp forests and the multitude of species interactions that they support may control ecosystem structure and functioning, mitigating environmental stress and enhancing resistance towards habitat loss or fragmentation (e.g. Bennett et al., 2015; Steneck et al., 2002). In kelp forests, sedimentation and accumulation of detritus (Airoldi, 2003; Duggins \& Eckman, 1994) are considered key features in structuring benthic assemblages. Moreover, shading effects (Arkema, Reed, \& Schroeter, 2009; Clark, Edwards, \& Foster, 2004) and depth gradient (Graham, 2004; Rodgers \& Shears, 2016) control their food webs, driven by the primary production provided by kelps and their epiphytes.

Ecological processes in terrestrial and kelp forests have been extensively investigated, while little is known about marine animal forests. Marine animal forests are made by dense assemblages of benthic suspension-feeders, filtering large quantities of seston and substantially contributing to the benthic-pelagic coupling (Gili, Coma, Orejas, López- 
Conway, Gibbs, Lamb, \& Gibbs, 2009), mono-specific forests of hydroids (Di Camillo et al., 2013; Rossi, Bramanti, Broglio, \& Gili, 2012), black corals (e.g. Bo, Canese, \& Bavestrello, 2014; Ingrassia et al., 2016), mesophotic zoantharians (e.g. gold coral) and gorgonians (Cartes, LoIacono, Mamouridis, Lopez-Perez, \& Rodriguez, 2013; Cerrano et al., 2010). One of the most peculiar elements characterizing Mediterranean coralligenous habitats (mesophotic biogenic reefs, sensu Ballesteros, 2006) are the forests of the gorgonian Paramuricea clavata (Risso 1826) (Musard et al., 2014). P. clavata is a long-lived, slowgrowing species (Linares, Doak, Coma, Díaz, \& Zabala, 2007). Colonies, irregularly branched and purple/yellow in colour, may be more than $1.5 \mathrm{~m}$ in height and over 100 years old (Linares, Doak, Coma, Díaz, \& Zabala, 2007). Pristine forests may reach densities of greater than 50 colonies $\mathrm{m}^{-2}$ and dry masses greater than $1,700 \mathrm{~g} \mathrm{~m}^{-2}$ (Coma, Ribes, Zabala, \& Gili, 1998; Linares, Coma, Garrabou, Díaz, \& Zabala, 2008). Biology and ecology of this species have been well studied: geographic and bathymetric distributions (Boavida, Assis, Silva, \& Serrão, 2016; Di Camillo, Ponti, Bavestrello, Krzelj, \& Cerrano, 2017; Gori et al., 2011; Kipson et al., 2015; see also Supplementary Material S1, Figure S1.1 and Figure S1.2), reproduction, growth, secondary production and survivorship (Coma, Ribes, Zabala, \& Gili, 1998; Cupido et al., 2012; Cupido, Cocito, Sgorbini, Bordone, \& Santangelo, 2008; Fava, Bavestrello, Valisano, \& Cerrano, 2010; Linares, Coma, \& Zabala, 2008; Linares, Doak, Coma, Díaz, \& Zabala, 2007; Mistri \& Ceccherelli, 1994; Santangelo et al., 2015), feeding ecology (Cocito et al., 2013; Coma, Gili, Zabala, \& Riera, 1994; Ribes, Coma, \& Gili, 1999), respiration rate (Coma, Ribes, Gili, \& Zabala, 2002; Previati, Scinto, Cerrano, \& Osinga, 2010), and population genetic structure (Mokhtar-Jamai et al., 2011; Perez-Portela et al., 2016; Pilczynska, Cocito, Boavida, Serrao, \& Queiroga, 2016).

Integrity of $P$. clavata forests, however, is threatened by fishing lines and nets, anchorages and recreational divers causing mechanical damage (Bavestrello, Cerrano, Zanzi, 
\& Cattaneo-Vietti, 1997; Linares \& Doak, 2010; Markantonatou, Marconi, \& Cerrano, 2016; Tsounis et al., 2012), suffocation by mucilaginous benthic aggregates (Giuliani, Virno Lamberti, Sonni, \& Pellegrini, 2005; Mistri \& Ceccherelli, 1996a), invasion from nonindigenous species (Cebrian, Linares, Marschal, \& Garrabou, 2012), and increase in water turbidity and sedimentation rates due to run-off as a result of bad land management (MateosMolina et al., 2015). Moreover, gorgonian forests are threatened by global climate changerelated disturbances such as increased frequency of exceptional storms (Teixido, Casas, Cebrian, Linares, \& Garrabou, 2013) and thermal anomalies (Cerrano \& Bavestrello, 2008; Linares, Coma, Garrabou, Díaz, \& Zabala, 2008) that may induce physiological stress and increase their susceptibility to pathogens (Calvo et al., 2011; Rivetti, Fraschetti, Lionello, Zambianchi, \& Boero, 2014; Vezzulli, Pezzati, Huete-Stauffer, Pruzzo, \& Cerrano, 2013). The latter, coupled with reduced food availability due to the stratification of the water column in summer, seem to lie at the basis of the gorgonian mass mortality events recorded in recent decades in the north-western Mediterranean Sea (Calvo et al., 2011; Cerrano et al., 2000; Crisci, Bensoussan, Romano, \& Garrabou, 2011; Garrabou et al., 2009; Huete-Stauffer et al., 2011; Linares et al., 2005; Martin, Bonnefort, \& Chancerelle, 2002).

Currently, many $P$. clavata forests are fragmented in patches and considered in strong regression as a result of mass mortality events that repeatedly affected this long-lived, slow growing and low resilient species (Cerrano et al., 2005; Cupido et al., 2009; Linares et al., 2005). Concerns for gorgonian forests, and for the consequences of their loss on the associated assemblages and on the ecological processes occurring in the understorey are rising, even if little is known on the structure, diversity and abundances of the benthic assemblages associated to $P$. clavata forest. Manipulative experiments have highlighted that P. clavata forests significantly affect the early-stage recruitment of sessile epibenthic 
assemblages, although effects may vary across sites exposed to different environmental

124 conditions (Ponti et al., 2014). assemblages inhabiting the understorey of Mediterranean P. clavata forests, compared to adjacent not forested rocky areas, and to shed light on the conservation needs of this habitat-

128 forming species to preserve biodiversity of coralligenous habitats.

\section{Materials and methods}

\subsection{Sampling design and survey method}

132 Epibenthic sessile assemblages inside and outside Paramuricea clavata forests were

133 investigated by applying a multifactorial sampling design. Nine sites were randomly selected

134 among those with a high abundance of $P$. clavata, as reported in the Reef Check database

135 (Cerrano, Milanese, \& Ponti, 2017; see Supplementary Material S1, Figure S1.1) (Figure 1).

136 At each site four areas inside and four outside P. clavata forests, having similar orientation,

137 inclination and depth $( \pm 3 \mathrm{~m})$, were randomly selected. Four photographic samples $(21 \times 28$

$138 \mathrm{~cm}$ ) were collected within each area (Figure 2a) using either a Canon PowerShot G12 or a

139 Canon PowerShot G15 digital cameras (10 to 12 Mpixel, respectively) equipped with an

140 aluminium underwater case, S-TTL strobe (Inon D-2000) and a custom stainless steel frame.

141 Inside gorgonian forests height and percentage cover of $P$. clavata colonies were measured in

142 the field and by photographic samples $(50 \times 50 \mathrm{~cm})$, respectively (Figure $2 \mathrm{~b}$ ).

143 Percentage cover of sessile organisms was quantified by superimposing a grid of 400

144 equal-sized squares, using the software PhotoQuad (Trygonis \& Sini, 2012). Although several

145 software are available to estimate the abundance of organisms in photographic samples, such

146 as SeaScape, based on picture segmentation (Teixido et al., 2011), and CPCe, based on

147 random points count (Kohler \& Gill, 2006), PhotoQuad was chosen because it allows to 
148 define the accuracy of the percentage cover estimation, based on the number of cells in the

149 superimposed grid, and does not set limits to the maximum number of identifiable species, as

150 occurs counting a set of random points. Percentage cover was related to the total readable area

151 of each image, obtained by subtracting dark and blurred zones or portions covered by motile

152 organisms as in Ponti, Fava, \& Abbiati (2011). Organisms were identified to the lowest

153 possible taxonomic level, by comparisons to close-up photos and voucher specimens collected

154 in previous studies (e.g. Ponti, Fava, \& Abbiati, 2011; Ponti et al., 2014), and grouped into

155 morpho-functional groups (modified from Casas-Güell, Teixidó, Garrabou, \& Cebrian, 2015;

156 Garrabou, Ballesteros, \& Zabala, 2002; Teixido, Garrabou, \& Harmelin, 2011). All calcifying

157 taxa were also included in the builder group.

\subsection{Data analysis}

160 Differences in height and percentage cover of Paramuricea clavata forests between sites were assessed by one-way Analysis of Variance (ANOVA, $\alpha=0.05$; Underwood, 1997).

Benthic assemblage similarities were calculated for each pair of samples using the

Bray-Curtis coefficient applied to square root-transformed percentage cover data and excluding $P$. clavata from the analysis (Clarke, 1993). Similarity patterns of benthic assemblage inside and outside gorgonian forest and among sites were represented by both unconstrained ordination plot, using the Principal Coordinate Analysis (PCoA; Gower, 1966),

167 and constrained ordination plot, using the Canonical Analysis of Principal coordinates (CAP;

168 Anderson \& Willis, 2003), calculated on the centroids of similarities among replicates from 169 the same sampling area. CAP detects the axis that best discriminate between the two $a$ priori 170 groups, i.e. benthic assemblages inside and outside gorgonian forest.

171 The possible relationship between the similarity patterns of the benthic assemblages 172 and environmental conditions and geographical locations (see Supplementary Material S2, 
173 Figure S2.1, Table S2.2) were investigated by multivariate multiple regression using the

174 DistLM procedure that provides a step-wise conditional selection of predictor variables

175 significantly correlated with the obtained similarity patterns (McArdle \& Anderson, 2001).

176 These relationships were graphically represented by vectors superimposed on the PCoA plot.

177 Differences in assemblage structures inside and outside gorgonian forest (Go: 2 levels,

178 fixed), among sites ( $\mathrm{Si}: 9$ levels, random), in the interaction $(\mathrm{Go} \times \mathrm{Si})$, and among areas

179 nested in this interaction $(\mathrm{Area}(\mathrm{Go} \times \mathrm{Si}))$ were assessed by permutational multivariate

180 analysis of variance (PERMANOVA, $\alpha=0.05$; Anderson $\&$ ter Braak, 2003). When less than

181999 unique values in the permutation distributions were available, asymptotical Monte Carlo

$182 p$-values $\left(p_{M C}\right)$ were used instead of permutational $p$-values. Results of the PERMANOVA

183 test were reported along with the estimated component of variation, in percentage of the total,

184 allowing to compare the relative importance of different terms in the model (Anderson,

185 Gorley, \& Clarke, 2008).

186 Species richness (as number of species, $S$ ), species diversity (as Hill's diversity

187 number $N 1=\operatorname{Exp} H^{\prime}$, where $H^{\prime}$ is the Shannon's index based on natural logarithm) and the

188 corresponding evenness component (as $N 10=N 1 / S)$ were calculated for each sample

189 (Magurran, 2004). N1 represent the 'effective number of species' of an assemblage, i.e. the

190 species richness of a perfectly even assemblage (all species equally common) with the same

191 diversity as the original assemblage (Hill, 1973).

192 Differences in single species percentage cover, morpho-functional groups percentage

193 cover and species diversity indices were assessed by mixed multifactorial ANOVA $(\alpha=0.05)$

194 following the same design adopted for PERMANOVA. Cochran's C test was used to check

195 the assumption of homogeneity of variances and, when necessary, data transformations were

196 applied. If variances were slightly heterogeneous even after transformations (Cochran's C test

$1970.05>p>0.01$ ), the analyses were run at $\alpha=0.01$ for significance test, while when variances 
were highly heterogeneous (Cochran's $C$ test $p<0.01$ ), the analyses were conservatively run

199 at $\alpha=0.001$ (Underwood, 1997). In the ANOVA, when the term Go $\times$ Si was not significant $200(p>0.25)$ it was pooled with the term Area(Go $\times \mathrm{Si})($ Underwood, 1997). When the term Go $201 \times$ Si was significant, the Student-Newman-Keuls (SNK) method was used for the post-hoc 202 comparisons.

Possible relations between the percentage cover of $P$. clavata and those of other taxa were explored by local polynomial regression fitting (LOESS), which is a smoothing method that summarizes the association between variables by fitting a multitude of regression models to adjacent subsets of the data (Cleveland \& Devlin, 1988). For this purpose, percentage cover data inside gorgonian forests were averaged by area (i.e. 4 areas per site).

Multivariate analyses were performed using PRIMER 6 with PERMANOVA+ add-on package (Anderson, Gorley, \& Clarke, 2008). LOESS and univariate analyses were made in R (R Core Team, 2017) with GAD, a specific package for General ANOVA Designs (SandriniNeto \& Camargo, 2012). Mean values were always reported along with their standard errors 212 (s.e.).

\section{Results}

\section{$215 \quad 3.1$ The investigated gorgonian forests}

216 The study sites were located over a wide geographical area, which spans $5.6^{\circ}$ in latitude and $2178.2^{\circ}$ in longitude, from the north-western Mediterranean Sea (P.te Causinière at Cap Ferrat, 218 Villefranche-sur-Mer and Colombara at Portofino, in the Ligurian Sea, Punta delle Cannelle, 219 Capo Calvo, Picchi di Pablo and Scoglio del Remaiolo at Elba Island in the central Tyrrhenian Sea) to the central Mediterranean (Punta San Paolo at Ustica Island) and to the northern Adriatic Sea (Zverinac Južni Rt and Rivanjski Kanal in Croatia). At study sites, gorgonian forests occur at different depths, with upper limits from 22 to $40 \mathrm{~m}$, either on 
vertical or horizontal substrates, with different orientations. Geological and environmental features at each site were reported in the Supplementary Material (S2, Figure S2.1, Table S2.1 and S2.2).

Gorgonian forests significantly differed between study sites both in terms of colony height $\left(F_{8,27}=6.38, p=0.0001\right)$ and percentage cover $\left(F_{8,27}=2.48, p=0.037\right)$. The mean gorgonian height ranges from $25.4 \pm 4.3 \mathrm{~cm}$ to $122.1 \pm 22.6 \mathrm{~cm}$; while their mean percentage cover ranges from $22.3 \pm 5.1 \%$ to $56.8 \pm 7.4 \%$ (Figure $2 \mathrm{c}, \mathrm{d}$; Figure 3 ).

\subsection{Epibenthic assemblages inside and outside gorgonian forests}

Besides Paramuricea clavata, 97 taxa were recorded and quantified, of which 45 were identified to species level. The allocation of taxa to morpho-functional groups has been reported in the Supplementary Material (S3, Table S3.1).

The most abundant and widely distributed taxa were encrusting calcareous rhodophytes belonging to Corallinaceae and Peyssonneliaceae families, and erect algae such as Flabellia petiolata (Turra) Nizamuddin 1987, Pseudochlorodesmis furcellata (Zanardini) Børgesen 1925 and Halimeda tuna (J.Ellis \& Solander) J.V.Lamouroux 1816. Some species, though locally abundant, were found only in nearby sites. It was the case of the colonial ascidians Polycitor adriaticus (Drasche 1883) and Aplidium conicum (Olivi 1792) that were recorded only in the northern Adriatic Sea (Figure 2c), and of the invasive alga Caulerpa cylindracea Sonder 1845 that was found at Elba Island (Figure 2e).

Benthic assemblages showed a large variability among sampling areas (i.e. local scale), which accounts for $19.7 \%$ of the total observed variation, and among sites $(28.1 \%$ of the total variation). Significant differences were also found in relation to the presence of gorgonian forest across sites (19.0\% of the total variation; Table 1). The variability of the benthic assemblages associated with the presence/absence of the gorgonian per se, 
independently from the geographical location, accounts for the $9.4 \%$ of the total observed

249 variation. Patterns of similarity among assemblages were strongly affected by differences

250 among sites rather than inside and outside gorgonian forests, as it is well represented in the

251 PCoA ordination plot (Figure 4a). In the unconstrained plot, the data cloud is driven by the

252 large geographical differences in assemblage structures, represented by the correlation vector

253 of the longitude, as well as by depth and substrate inclination. Inclination, depth and latitude

254 were selected by the DistLM step-wise procedure as the best combination of variables

255 significantly correlated to the obtained similarity pattern and together explain $46.8 \%$ of the

256 total variation in benthic assemblages. The variability among sites tends to mask the effects of

257 the presence of gorgonians, however detected by PERMANOVA test (Table 1). Conversely,

258 the constrained ordination plot, obtained by CAP, revealed a clear differentiation between

259 assemblages inside and outside gorgonian forest, with a large canonical correlation of 0.87

260 (Figure $4 b$ ).

261 Few species, individually analysed, showed a clear pattern in relation to the

262 occurrence of gorgonian forest. The green algae Codium bursa (Olivi) C.Agardh 1817 was

263 found at five sites out of nine, and always only outside P. clavata forest. The yellow

264 gorgonian Eunicella cavolini (Koch 1887) was found at six sites out of nine, and at five of

265 these was present only inside P. clavata forest. However, ANOVA tests failed to detect a

266 significant effect of the gorgonian forest on the abundance of C. bursa and E. cavolini due to

267 the paucity of data and heterogeneity of variances (Table 2). Overall, the percentage covers of

268 encrusting sponges (from zero to $9.9 \pm 1.6 \%$ ) and encrusting bryozoans (from zero to $6.1 \pm$

$2691.5 \%$ ) were very variable at the local and regional scales, i.e. among areas and sites, and in

270 both cases they were significantly more abundant inside the gorgonian forests (Table 2,

271 Figure 5a,b). The percentage covers of erect bryozoans varied from $0.03 \pm 0.03 \%$ to $6.1 \pm$

$2723.0 \%$ and showed a less clear pattern with a large variability at the local scale. Their 
273 abundance inside and outside gorgonian forests was not consistent across sites (Table 2). The

274 SNK test revealed that their percentage covers were significantly higher inside the gorgonian

275 forests at three sites, while at the six other sites no differences were detected (Figure 5c).

276 Mixed turf, which includes many filamentous algae and hydroids, showed percentage covers

277 ranging from $6.6 \pm 3.3 \%$ and $52.6 \pm 4.7 \%$ with significant variability at local scale (Table 2 ).

278 Its abundance inside and outside gorgonian forests was not consistent across sites. In this

279 case, the SNK test revealed that its percentage covers were significantly higher outside the

280 gorgonian forests at seven sites, while at the two remaining sites no differences were detected

281 (Figure 5d). Percentage cover of the encrusting calcareous rhodophytes (ECR), ranging from

$2821.3 \pm 0.6 \%$ to $26.7 \pm 3.2 \%$, significantly varied among sites and showed higher values inside

283 gorgonian forest (Table 2, Figure 5e). Similar results were obtained by summing encrusting

284 calcareous rhodophytes with all the other builder organisms that may contribute to the

285 coralligenous framework (Table 2, Figure 5f).

Percentage covers of green algal turfs and non-encrusting algae belonging to the genus

Peyssonnelia, although not significantly different between inside and outside the gorgonian

288 forests, showed a peculiar pattern in relation to the cover of $P$. clavata inside the forests. At

289 low gorgonian cover (up to $30 \%$ ), green algal turfs seemed to be facilitated by $P$. clavata,

290 while Peyssonnelia spp. were not affected (Figure 6a,b). At higher gorgonian cover, the

291 percentage covers of both algal groups decreased dramatically, down to about $10 \%$. The non-

292 indigenous alga Caulerpa cylindracea was found only at three sites located at Elba Island. At

293 these three sites, the percentage cover of $C$. cylindracea showed large variability at the local

294 scale (i.e. significant differences among areas) and significantly lower values inside the

295 gorgonian forests (Table 2, Figure 7a). Mucilaginous aggregates were found at only three

296 sites: Colombara at Portofino, Punta San Paolo at Ustica Island and Picchi di Pablo at Elba

297 Island (Figure 2f). At these three sites, the percentage cover of these aggregates showed large 
variability at the local scale and a significant variation across sites and inside vs outside gorgonian forest (Table 2). The SNK test revealed that percentage covers were significantly higher outside the gorgonian forests at two sites out of three sites (Figure 7b).

All the species diversity indices $(S, N 1$ and $N 10)$ showed significant variability at local scale, i.e. among areas within the interaction between site and gorgonian forest. Species richness $(S)$ and evenness (N10) significantly differed among sites. Overall, all indices were significantly higher inside the gorgonian forests (Table 2, Figure 8).

\section{Discussion}

This study compared the epibenthic assemblages inside and outside gorgonian forests across a broad range of central and western Mediterranean coralligenous habitats, differing in environmental conditions and belonging to different biogeographic sectors (sensu Bianchi \& Morri, 2000). Gorgonian forests vary in colony density, and dwell on rocky substrates differing in inclination, orientation and depth. Overall, understorey assemblages of these animal forests showed a large variability at different spatial scales. The percentages of component of variation of benthic assemblage structures at local (i.e. areas) and regional (i.e. sites) scales were comparable to those obtained in a previous study carried out by means of photographic samples inside P. clavata forests in the NW Mediterranean Sea (Casas-Güell, Teixidó, Garrabou, \& Cebrian, 2015). None of the species found in this study are exclusive of either forested or not forested habitats, nor closely associated with the presence of P. clavata.

318 Nevertheless, at the local scale, the structures of the epibenthic assemblages significantly

319 differed between inside and outside the gorgonian forests. The Mediterranean yellow gorgonian Eunicella cavolini is often associated with the $P$. clavata forests. Interspersion between colonies of E. cavolini and P. clavata, as observed in the present study, is a common finding through all the Mediterranean Sea (Di Camillo, Ponti, 
323 Bavestrello, Krzelj, \& Cerrano, 2017). This suggests a large overlap in their ecological niche

324 and limited interspecific competition, at least at low colony densities. E. cavolini colonies are smaller in size, have a slower growth rate, an higher $\mathrm{P} / \mathrm{B}$ ratio, and a lower turnover rate compared to P. clavata (Coma, Ribes, Zabala, \& Gili, 1998 and references therein). These two gorgonians are affected by the same local and global threats (Cerrano et al., 2000; Garrabou et al., 2009; Sini, Kipson, Linares, Koutsoubas, \& Garrabou, 2015), although E. cavolini, in a field experiment, showed greater resistance to thermal stress, with a lower mortality and a higher recovery capacity compared to P. clavata (Fava, Bavestrello, Valisano, \& Cerrano, 2010). Forests of $P$. clavata being larger in size may protect E. cavolini and other fragile species, such as erect bryozoans, from mechanical damage (e.g. fishing lines, nets and divers), as already documented for Pentapora fascialis (Pallas 1766) by Garrabou, Sala, Arcas, \& Zabala (1998).

Compared to the unforested rocky bottoms, the understorey of $P$. clavata forests host higher percentage covers of encrusting sponges, encrusting bryozoans and encrusting calcareous rhodophytes. All of them are relevant components of the Mediterranean coralligenous habitats and contribute to their frameworks (Ballesteros, 2006). Recruitment of encrusting sponges and encrusting bryozoans may be facilitated by the presence of $P$. clavata, as consistently observed in early-stage recruitment experiments carried out in the Ligurian 341 and the Tyrrhenian Sea (Ponti et al., 2014). The reduction of light intensity and sediment 342 accumulation induced by gorgonian branches may favour the competitive success of 343 encrusting calcareous rhodophytes, as observed under canopies of marine plant and 344 demonstrated by manipulating this physical factors in subtidal rocky habitats (Airoldi, 2003; 345 Connell, 2005; Connell, 2003; Irving \& Connell, 2002). Overall, by summing all organisms able to deposit calcium carbonate it turns out that 347 these forests support higher abundances of builder organisms. These findings suggest that 
gorgonian forests may largely contribute to maintaining and developing coralligenous

349 biogenic habitats. On the contrary, mixed turfs of filamentous algae and hydroids, which 350 normally tend to compete for space with encrusting sponges, encrusting bryozoans and 351 encrusting calcareous rhodophytes, were often more abundant outside the gorgonian forests. Codium bursa, was found only outside the forests. The growth of this long-lived and slow-growing alga, is generally limited by nutrient availability (especially phosphorus), rather than by light (Vidondo \& Duarte, 1995). This suggests that the limiting effect of $P$. clavata towards this seaweed go well beyond the simple shading and likely acts at the early recruitment stage.

At high gorgonian density, edaphic conditions (e.g. physical factors such as light, currents, sedimentation rates) may be strongly modified, increasing habitat complexity that supporting many necto-benthic organisms (Cerrano et al., 2010; Ponti et al., 2016; Valisano, Notari, Mori, \& Cerrano, 2016). This study highlighted that the direct or indirect effects of the gorgonians on the abundance of other species, as green algal turfs and non-encrusting peyssonneliacean algae, may vary by gorgonians density, in terms of percentage cover. Indeed, the effects of gorgonians on erect and filamentous algae could vary with colony 364 densities, sites and depths, as observed in the early-stage recruitment experiments (Ponti et al., 2014). The reduction in the abundance of some algal species seems to occur when the gorgonian cover exceeds $30 \%$. This value could be considered a threshold to detect a shading

367 effect and therefore a reference value in the assessment of the health status of the forests. 368 However, density-dependent interactions in marine animal forests are far from being 369 understood and deserve further investigations. Higher values of species diversity indices were found inside gorgonian forests, 371 compared to surrounding rocky bottoms. This trend is consistent across the investigated 
geographical area, corroborating the hypothesis of a positive relationship between three-

373 dimensional habitat complexity and species diversity (Kovalenko, Thomaz, \& Warfe, 2012).

\subsection{A focus on the non-indigenous species Caulerpa cylindracea}

Non-indigenous species (NIS) have been recognized as a threat to the integrity of

Mediterranean native communities. Establishment of NIS can drastically change the structure of marine communities, affecting species growth rates, survival and reproduction (Butchart et al., 2010; Occhipinti-Ambrogi, 2007). The green alga Caulerpa cylindracea is listed among the most threatening Mediterranean invaders (Streftaris \& Zenetos, 2006), and represents one of the major concerns for the coralligenous habitats (Piazzi, Balata, \& Cinelli, 2007; Piazzi,

382 Gennaro, \& Balata, 2012). Manipulative experiments showed that the presence of $C$.

383 cylindracea negatively affects the Paramuricea clavata fitness by increasing the percentage of necrosis and lowering biomass and survivorship (Cebrian, Linares, Marschal, \& Garrabou, 2012). However, the role of gorgonian forests in preventing the settlement and invasion of $C$. cylindracea has never been investigated. At all sites where it occurred C. cylindracea was significantly less abundant inside gorgonian forests. The result seems fairly robust and suggests a resistance of the gorgonians to the invasion of this seaweed. Piazzi, Balata, Bulleri,

389 Gennaro, \& Ceccherelli (2016), in a recent review on biotic and abiotic interactions of $C$. cylindracea in the Mediterranean Sea, suggested that canopy-forming algae and seagrasses

391 may limit the spread of $C$. cylindracea by reducing photosynthetic performance by shading.

392 Gorgonian forests may cause similar shadow effects. Moreover, P. clavata may directly or 393 indirectly reduce the recruitment of $C$. cylindracea by releasing allelochemicals (Rodriguez, 394 1995) or limiting the abundance of algal turfs, which may enhance the spread of the invader 395 (Piazzi, Balata, Bulleri, Gennaro, \& Ceccherelli, 2016 and references therein). 


\subsection{Entrapment of mucilaginous aggregates}

Developments of mucilaginous aggregates are recurrent events in the Mediterranean

Sea (Rinaldi, Vollenweider, Montanari, Ferrari, \& Ghetti, 1995; Sartoni et al., 2008).

Deposition of mucilaginous aggregates on the seabed may cause severe damage to many benthic organisms, by reducing light availability, suffocating sessile invertebrates and establishing anoxic conditions (Schiaparelli, Castellano, Povero, Sartoni, \& Cattaneo-Vietti, 2007). Gorgonians are very sensitive to mucilage, which can cause necrosis of coenenchyme and leave portions of axial skeleton bare (Giuliani, Virno Lamberti, Sonni, \& Pellegrini, 2005; Mistri \& Ceccherelli, 1996a). Paramuricea clavata colonies may recover from damage caused by mucilage in a few years through recruiting juvenile colonies (Mistri \& Ceccherelli, 1996b). The present study shows that gorgonians may reduce the accumulation in the understorey by trapping the mucilaginous aggregates with their branches. Gorgonian forests, although at expense to themselves, may therefore limit the damage from suffocation to many associated benthic invertebrates.

\section{Conclusions}

The ecological role played by habitat-forming species cannot be easily disentangled, either from a physical or biological perspective. Generally, increased habitat complexity leads to higher species diversity in the associated assemblages, by increasing the available space and the number of microhabitats (Kovalenko, Thomaz, \& Warfe, 2012). Moreover, the habitat complexity built up by ecosystem engineers induces physical changes, but may also modify many biological processes, with unpredictable ecological effects (Kelaher, 2003). Although the mechanisms underlying these processes are still not well known, forests of Paramuricea clavata, besides modifying microscale hydrodynamics, may provide additional food resources, being an effective suspension feeder able to modify littoral marine food webs 
422 (Coma, Gili, Zabala, \& Riera, 1994; Gili \& Coma, 1998), increase refuges and available 423 surface area (Ponti et al., 2016; Valisano, Notari, Mori, \& Cerrano, 2016), as well as affect 424 recruitment processes (Ponti et al., 2014). According to the present results, these animal 425 forests are supporting high species diversity and promote bioconstruction processes in their 426 understorey. Presence of long-lived gorgonians may contribute to reducing the temporal 427 variability of epibenthic assemblages, as already reported for Mediterranean coralligenous 428 habitats (Casas-Güell, Teixidó, Garrabou, \& Cebrian, 2015; Teixido, Garrabou, \& Harmelin, 429 2011). Indeed, healthy gorgonian forests may also oppose to the spread of non-indigenous 430 species and mitigate the effects of adverse events, like mucilage formations. Gorgonian 431 species play an ecological role that goes well beyond the aesthetic value, which attracts a 432 large number of recreational divers (Musard et al., 2014). The obtained results support the 433 concern raised by several scientists about the loss of habitat complexity caused by extensive 434 mass mortalities of Mediterranean gorgonians (Cerrano \& Bavestrello, 2008). The 435 fragmentation and the local disappearance of gorgonian forests could cause severe and sudden 436 modifications of associated epibenthic communities. It may lower species diversity, alter 437 ecosystem functioning, and reduce the resistance and resilience of the assemblages with 438 concomitant losses of ecological goods and services, over different spatial and temporal 439 scales. Paramuricea clavata is considered a "vulnerable" species according to the

440 Mediterranean Red List (ver. 3.1) provided by IUCN, mainly because of its low recruitment 441 rate, and the facies with P. clavata is listed in the habitats that deserve special protection 442 under the Barcelona Convention (RAC/SPA, Tunis). Evidence from this and many other 443 studies strongly suggest the need to consider the health status of this species and of the forests 444 it shapes, threatened by several anthropogenic disturbance and by the global climate changes, 445 as essential elements of the ecological dynamics of the Mediterranean Sea, and therefore 446 worthy of specific and effective transboundary protection measures. The European Marine 
447 Strategy Framework Directive (2008/56/EC), the environmental pillar of the Blue Growth 448 strategy, defines the need of each member state to reach Good Environmental Status (GES) of 449 their marine waters. This achievement should require an urgent regulation of fishing activity, 450 anchorages and scuba diving where gorgonian forests are present and restoration activities 451 when evident alterations are documented. The results here presented clearly indicate that $P$. 452 clavata represent a key species to maintain the GES of the Mediterranean temperate reefs, the 453 coralligenous habitats.

454 Our results suggest that the health status of $P$. clavata forests could be monitored by using 455 physical and structural descriptors, related to the magnitude of their positive effects on the 456 complexity of benthic assemblages. The descriptors should include depth (range or upper 457 limit of the forest), bottom inclination and orientation, mean colony height and percentage 458 cover of the colonies. Furthermore, the percentage cover of bioconstructors in the understorey 459 could be considered as a proxy of the effectiveness protection offered by gorgonians to the 460 benthic community. Bioconstructors are a key component in maintaining coralligenous 461 habitats and their species diversity. Other important aspects that should be monitored are the 462 degree of fragmentation of the forest, the extent of bare skeletons and necrotic portions of 463 coenenchyme. Human impacts on gorgonian forest could be quantified by measuring the 464 amount of fishing lines and nets entangled in colonies, which may cause lesions, while the 465 quantity of epibionts may provide information on how long they have been damaged by 466 humans or by natural events.

467 Several actions should be undertaken to protect gorgonian forests starting from the reduction 468 of local human disturbances (both al the coast and inland; Mateos-Molina et al., 2015), 469 establishing and enforcing properly designed and regulated marine protected areas 470 (Arizmendi-Mejía et al., 2015; Coma, Pola, Ribes, \& Zabala, 2004; Linares \& Doak, 2010), 471 and considering the aesthetic values of seascapes in conservation policies (Chimienti et al., 
2017). However, while much can be done for the conservation of healthy marine animal

473 forests, methodologies for the maintenance and restoration, that have been successfully

474 applied in coral reefs (e.g. Epstein, Bak, \& Rinkevich, 2001; Jaap, 2000; Rinkevich, 2005;

475 Young, Schopmeyer, \& Lirman, 2012), are not yet available for temperate gorgonian forests.

476 Maintenance actions may consist in removing fishing lines and nets that have a prolonged

477 action over time (Bavestrello, Cerrano, Zanzi, \& Cattaneo-Vietti, 1997) and pruning the top

478 of branches in order to remove lesioned and compromised parts, allowing for regrowth

479 (Previati et al., 2011; Sánchez-Tocino, De La Linde Rubio, Lizana Rosas, Pérez Guerra, \&

480 Tierno De Figueroa, 2018). Transplantation techniques are under development (Fava,

481 Bavestrello, Valisano, \& Cerrano, 2010; Linares, Coma, \& Zabala, 2008; Montero-Serra et

482 al., 2018) and could be effective in order to restore lost and damaged forests. Owing to the

483 continuous risks of thermal anomalies due to climate change, these restoring approaches

484 should be addressed below the average depth of the summer thermocline. These approaches

485 are very promising, especially if chronic and persistent human disturbances are removed

486 before interventions. Integration of biological experiments with the eco-engineering

487 approaches has been proved to be successful in restoration of coastal ecosystems and the

488 possibilities to use it also on temperate mesophotic biogenic reefs should be properly

489 explored.

\section{Acknowledgements}

492 Photographic sampling was carried out in accordance with national laws and no organism has

493 been removed or damaged. We wish to thank Chiara Luciani and Pier Giacomo De Cecco

494 (marine biologists at Biodivers dive centre, Elba Island), Andrea Galliadi (marine biologist at

495 the Diving Evolution Portofino), Adelmo Sorci (Marlintremiti dive centre), Giovanni Pezzi 
(Diving Center Ugljan, Croatia), Roberto Fedele (Perla Nera Diving, Ustica) and the staff of

497 the Rand'eau évasion (Villefranche-sur-Mer) for the valuable diving assistance.

498 This work has been partially supported by two Research Projects of National Interest (PRIN),

499 funded by the Italian Ministry of University and Research: "Coastal bioconstructions:

500 structures, functions, and management" (Call 2010-2011; Prot. 2010Z8HJ5M; 2013-2015)

501 and "Reef ReseArcH - Resistance and resilience of Adriatic mesophotic biogenic habitats to

502 human and climate change threats" (Call 2015; Prot. 2015J922E; 2017-2020), and by the

503 European Union's project "Marine Ecosystem Restoration in Changing European Seas"

504 (MERCES; Horizon 2020; Grant Agreement no.: 689518). Moreover, part of the field work

505 was carried out within the "Training Network for Monitoring Mediterranean Marine Protected

506 Areas" (MMMPA), a Marie Curie Initial Training Network (Call FP7-PEOPLE-2011-ITN;

507 Grant Agreement no.: 290056; 2012-2015). This work is part of ET PhD. ET took benefit of a

508 EuroMarine Young Scientist Fellowship within its Programme for Training. This study has

509 been conducted using E.U. Copernicus Marine Service Information.

510

$511 \quad$ References

512 Airoldi, L. (2003). The effects of sedimentation on rocky coast assemblages. Oceanography and Marine Biology: An Annual Review, 41, 161-236.

514 Anderson, M. J., Gorley, R. N., Clarke, K. R. (2008). PERMANOVA+ for PRIMER: Guide to 515 software and statistical methods. Plymouth, UK: PRIMER-E Ltd.

516 Anderson, M. J., ter Braak, C. J. F. (2003). Permutation tests for multi-factorial analysis of 517 variance. Journal of Statistical Computation and Simulation, 73, 85-113.

518 Anderson, M. J., Willis, T. J. (2003). Canonical analysis of principal coordinates: A new 519 ecologically meaningful approach for constrained ordination. Ecology, 84, 511-525. 
Arizmendi-Mejía, R., Linares, C., Garrabou, J., Antunes, A., Ballesteros, E., Cebrian, E., ... Ledoux, J.-B. (2015). Combining genetic and demographic data for the conservation of a Mediterranean marine habitat-forming species. PLOS ONE, 10, e0119585.

Arkema, K. K., Reed, D. C., Schroeter, S. C. (2009). Direct and indirect effects of giant kelp determine benthic community structure and dynamics. Ecology, 90, 3126-3137.

Ballesteros, E. (2006). Mediterranean coralligenous assemblages: A synthesis of present knowledge. Oceanography and Marine Biology: An Annual Review, 44, 123-195.

Bavestrello, G., Cerrano, C., Zanzi, D., Cattaneo-Vietti, R. (1997). Damage by fishing activities in the gorgonian coral Paramuricea clavata in the Ligurian Sea. Aquatic Conservation-Marine and Freshwater Ecosystems, 7, 253-262.

Bennett, S., Wernberg, T., de Bettignies, T., Kendrick, G. A., Anderson, R. J., Bolton, J. J., ... Christie, H. C. (2015). Canopy interactions and physical stress gradients in subtidal communities. Ecology Letters, 18, 677-686.

Bianchi, C. N., Morri, C. (2000). Marine biodiversity of the Mediterranean Sea: Situation, problems and prospects for future research. Marine Pollution Bulletin, 40, 367-376.

Bo, M., Canese, S., Bavestrello, G. (2014). Discovering Mediterranean black coral forests: Parantipathes larix (Anthozoa: Hexacorallia) in the Tuscan Archipelago, Italy. Italian Journal of Zoology, 81, 112-125.

Boavida, J., Assis, J., Silva, I., Serrão, E. A. (2016). Overlooked habitat of a vulnerable gorgonian revealed in the Mediterranean and Eastern Atlantic by ecological niche modelling. Scientific Reports, 6, 36460.

Butchart, S. H. M., Walpole, M., Collen, B., van Strien, A., Scharlemann, J. P. W., Almond, R. E. A., ... Watson, R. (2010). Global biodiversity: Indicators of recent declines. Science, $328,1164-1168$. 
544 Calvo, E., Simo, R., Coma, R., Ribes, M., Pascual, J., Sabates, A., ... Pelejero, C. (2011).

545 Effects of climate change on Mediterranean marine ecosystems: The case of the Catalan $546 \quad$ Sea. Climate Research, 50, 1-29.

547 Cartes, J. E., LoIacono, C., Mamouridis, V., Lopez-Perez, C., Rodriguez, P. (2013).

548 Geomorphological, trophic and human influences on the bamboo coral Isidella elongata 549 assemblages in the deep Mediterranean: To what extent does Isidella form habitat for fish $550 \quad$ and invertebrates? Deep-Sea Research Part I-Oceanographic Research Papers, 76, 52-65.

551 Casas-Güell, E., Teixidó, N., Garrabou, J., Cebrian, E. (2015). Structure and biodiversity of 552 coralligenous assemblages over broad spatial and temporal scales. Marine Biology, 162, $553 \quad 901-912$.

554 Cebrian, E., Linares, C., Marschal, C., Garrabou, J. (2012). Exploring the effects of invasive 555 algae on the persistence of gorgonian populations. Biological Invasions, 14, 2647-2656.

556 Cerrano, C., Arillo, A., Azzini, F., Calcinai, B., Castellano, L., Muti, C., ... Bavestrello, G. 557 (2005). Gorgonian population recovery after a mass mortality event. Aquatic $558 \quad$ Conservation-Marine and Freshwater Ecosystems, 15, 147-157.

559 Cerrano, C., Bavestrello, G. (2008). Medium-term effects of die-off of rocky benthos in the 560 Ligurian Sea. What can we learn from gorgonians? Chemistry and Ecology, 24, 73-82.

561 Cerrano, C., Bavestrello, G., Bianchi, C. N., Cattaneo-Vietti, R., Bava, S., Morganti, C., ... 562 Sponga, F. (2000). A catastrophic mass-mortality episode of gorgonians and other 563 organisms in the Ligurian Sea (Northwestern Mediterranean), summer 1999. Ecology $564 \quad$ Letters, 3, 284-293.

565 Cerrano, C., Danovaro, R., Gambi, C., Pusceddu, A., Riva, A., Schiaparelli, S. (2010). Gold 566 coral (Savalia savaglia) and gorgonian forests enhance benthic biodiversity and ecosystem 567 functioning in the mesophotic zone. Biodiversity and Conservation, 19, 153-167. 
568 Cerrano, C., Milanese, M., Ponti, M. (2017). Diving for science - science for diving:

569 Volunteer scuba divers support science and conservation in the Mediterranean Sea.

$570 \quad$ Aquatic Conservation: Marine and Freshwater Ecosystems, 27, 303-323.

571 Chimienti, G., Stithou, M., Mura, I. D., Mastrototaro, F., D'Onghia, G., Tursi, A., ...

572 Fraschetti, S. (2017). An explorative assessment of the importance of mediterranean

573 coralligenous habitat to local economy: The case of recreational diving. Journal of

$574 \quad$ Environmental Accounting and Management, 5, 315-325.

575 Clark, R. P., Edwards, M. S., Foster, M. S. (2004). Effects of shade from multiple kelp

576 canopies on an understory algal assemblage. Marine Ecology Progress Series, 267, $107-$ $577 \quad 119$.

578 Clarke, K. R. (1993). Non-parametric multivariate analyses of changes in community $579 \quad$ structure. Australian Journal of Ecology, 18, 117-143.

580 Cleveland, W. S., Devlin, S. J. (1988). Locally weighted regression: An approach to 581 regression-analysis by local fitting. Journal of the American Statistical Association, 83, $582 \quad 596-610$.

583 Cocito, S., Ferrier-Pages, C., Cupido, R., Rottier, C., Meier-Augenstein, W., Kemp, H., ... 584 Peirano, A. (2013). Nutrient acquisition in four Mediterranean gorgonian species. Marine $585 \quad$ Ecology Progress Series, 473, 179-188.

586 Coma, R., Gili, J. M., Zabala, M., Riera, T. (1994). Feeding and prey capture cycles in the 587 aposymbiontic gorgonian Paramuricea clavata. Marine Ecology Progress Series, 115, $588 \quad 257-270$.

589 Coma, R., Pola, E., Ribes, M., Zabala, M. (2004). Long-term assessment of temperate 590 octocoral mortality patterns, protected vs. unprotected areas. Ecological Applications, 14, $591 \quad 1466-1478$. 
Coma, R., Ribes, M., Gili, J. M., Zabala, M. (2002). Seasonality of in situ respiration rate in three temperate benthic suspension feeders. Limnology and Oceanography, 47, 324-331.

Coma, R., Ribes, M., Zabala, M., Gili, J. M. (1998). Growth in a modular colonial marine invertebrate. Estuarine Coastal and Shelf Science, 47, 459-470.

Connell, S. D. (2003). The monopolization of understorey habitat by subtidal encrusting coralline algae: a test of the combined effects of canopy-mediated light and sedimentation. Marine Biology, 142, 1065-1071.

Connell, S. D. (2005). Assembly and maintenance of subtidal habitat heterogeneity: synergistic effects of light penetration and sedimentation. Marine Ecology-Progress Series, 289, 53-61.

Crisci, C., Bensoussan, N., Romano, J.-C., Garrabou, J. (2011). Temperature anomalies and mortality events in marine communities: Insights on factors behind differential mortality impacts in the NW Mediterranean. PLoS ONE, 6, e23814.

Cupido, R., Cocito, S., Barsanti, M., Sgorbini, S., Peirano, A., Santangelo, G. (2009). Unexpected long-term population dynamics in a canopy-forming gorgonian coral following mass mortality. Marine Ecology Progress Series, 394, 195-200.

Cupido, R., Cocito, S., Manno, V., Ferrando, S., Peirano, A., Iannelli, M., ... Santangelo, G. (2012). Sexual structure of a highly reproductive, recovering gorgonian population: Quantifying reproductive output. Marine Ecology Progress Series, 469, 25-36.

Cupido, R., Cocito, S., Sgorbini, S., Bordone, A., Santangelo, G. (2008). Response of a gorgonian (Paramuricea clavata) population to mortality events: Recovery or loss? Aquatic Conservation-Marine and Freshwater Ecosystems, 18, 984-992.

Di Camillo, C. G., Boero, F., Gravili, C., Previati, M., Torsani, F., Cerrano, C. (2013). Distribution, ecology and morphology of Lytocarpia myriophyllum (Cnidaria: Hydrozoa), 

787.

618 Di Camillo, C. G., Ponti, M., Bavestrello, G., Krzelj, M., Cerrano, C. (2017). Building a 619 baseline for habitat-forming corals by a multi-source approach, including Web Ecological 620 Knowledge. Biodiversity and Conservation, DOI: 10.1007/s10531-017-1492-8

621 Duggins, D. O., Eckman, J. E. (1994). The role of kelp detritus in the growth of benthic 622 suspension feeders in an understory kelp forest. Journal of Experimental Marine Biology and Ecology, 176, 53-68.

624

625 626

Epstein, N., Bak, R. P. M., Rinkevich, B. (2001). Strategies for gardening denuded coral reef areas: The applicability of using different types of coral material for reef restoration. Restoration Ecology, 9, 432-442.

Fava, F., Bavestrello, G., Valisano, L., Cerrano, C. (2010). Survival, growth and regeneration in explants of four temperate gorgonian species in the Mediterranean Sea. Italian Journal of Zoology, 77, 44-52.

Garrabou, J., Ballesteros, E., Zabala, M. (2002). Structure and dynamics of north-western Mediterranean rocky benthic communities along a depth gradient. Estuarine, Coastal and Shelf Science, 55, 493-508.

Garrabou, J., Coma, R., Bensoussan, N., Bally, M., Chevaldonne, P., Cigliano, M., ... Cerrano, C. (2009). Mass mortality in Northwestern Mediterranean rocky benthic communities: Effects of the 2003 heat wave. Global Change Biology, 15, 1090-1103.

Garrabou, J., Sala, E., Arcas, A., Zabala, M. (1998). The impact of diving on rocky sublittoral communities: A case study of a bryozoan population. Conservation Biology, 12, 302-312.

Gili, J.-M., Coma, R., Orejas, C., López-González, P. J., Zabala, M. (2001). Are Antarctic suspension-feeding communities different from those elsewhere in the world? Polar Biology, 24, 473-485. 
641 Gili, J. M., Coma, R. (1998). Benthic suspension feeders: Their paramount role in littoral 642 marine food webs. Trends in Ecology \& Evolution, 13, 316-321.

643 Giuliani, S., Virno Lamberti, C., Sonni, C., Pellegrini, D. (2005). Mucilage impact on 644 gorgonians in the Tyrrhenian Sea. Science of the Total Environment, 353, 340-349.

645 Gori, A., Rossi, S., Berganzo, E., Pretus, J., Dale, M., Gili, J.-M. (2011). Spatial distribution 646 patterns of the gorgonians Eunicella singularis, Paramuricea clavata, and Leptogorgia 647 sarmentosa (Cape of Creus, Northwestern Mediterranean Sea). Marine Biology, 158, 153$648 \quad 158$.

649 Gower, J. C. (1966). Some distance properties of latent root and vector methods used in 650 multivariate analysis. Biometrika, 53, 325-338.

651 Graham, M. H. (2004). Effects of local deforestation on the diversity and structure of southern 652 California giant kelp forest food webs. Ecosystems, 7, 341-357.

653 Hill, M. O. (1973). Diversity and evenness: A unifying notation and its consequences. $654 \quad$ Ecology, 54, 427-432.

655 Huete-Stauffer, C., Vielmini, I., Palma, M., Navone, A., Panzalis, P., Vezzulli, L., ... Cerrano, 656 C. (2011). Paramuricea clavata (Anthozoa, Octocorallia) loss in the Marine Protected 657 Area of Tavolara (Sardinia, Italy) due to a mass mortality event. Marine Ecology-an 658 Evolutionary Perspective, 32, 107-116.

659 Ingrassia, M., Macelloni, L., Bosman, A., Chiocci, F. L., Cerrano, C., Martorelli, E. (2016). 660 Black coral (Anthozoa, Antipatharia) forest near the western Pontine Islands (Tyrrhenian 661 Sea). Marine Biodiversity, 46, 285-290.

662 Irving, A. D., Connell, S. D. (2002). Sedimentation and light penetration interact to maintain 663 heterogeneity of subtidal habitats: Algal versus invertebrate dominated assemblages. 664 Marine Ecology-Progress Series, 245, 83-91.

665 Jaap, W. C. (2000). Coral reef restoration. Ecological Engineering, 15, 345-364. 
Jones, C. G., Lawton, J. H., Shachak, M. (1994). Organisms as ecosystem engineers. Oikos, 69, 373-386.

Kelaher, B. P. (2003). Changes in habitat complexity negatively affect diverse gastropod assemblages in coralline algal turf. Oecologia, 135, 431-441.

Kipson, S., Linares, C., Čižmek, H., Cebrián, E., Ballesteros, E., Bakran-Petricioli, T., Garrabou, J. (2015). Population structure and conservation status of the red gorgonian Paramuricea clavata (Risso, 1826) in the Eastern Adriatic Sea. Marine Ecology, 36, 982993.

Kohler, K. E., Gill, S. M. (2006). Coral Point Count with Excel extensions (CPCe): A Visual Basic program for the determination of coral and substrate coverage using random point count methodology. Computers \& Geosciences, 32, 1259-1269.

Kovalenko, K. E., Thomaz, S. M., Warfe, D. M. (2012). Habitat complexity: Approaches and future directions. Hydrobiologia, 685, 1-17.

Linares, C., Coma, R., Diaz, D., Zabala, M., Hereu, B., Dantart, L. (2005). Immediate and delayed effects of a mass mortality event on gorgonian population dynamics and benthic

Linares, C., Coma, R., Garrabou, J., Díaz, D., Zabala, M. (2008). Size distribution, density and disturbance in two Mediterranean gorgonians: Paramuricea clavata and Eunicella singularis. Journal of Applied Ecology, 45, 688-699. 437. 
Linares, C., Doak, D. F. (2010). Forecasting the combined effects of disparate disturbances on

690 the persistence of long-lived gorgonians: A case study of Paramuricea clavata. Marine 691 Ecology Progress Series, 402, 59-68.

692 Linares, C., Doak, D. F., Coma, R., Díaz, D., Zabala, M. (2007). Life history and viability of 693 a long-lived marine invertebrate: The octocoral Paramuricea clavata. Ecology, 88, 918694928.

695 Magurran, A. E. (2004). Measuring biological diversity. Blakwell Science Ltd.

696 Markantonatou, V., Marconi, M., Cerrano, C. (2016). Guidelines for monitoring pressure and 697 impacts from small scale and recreational fishing activity in Mediterranean Marine 698 Protected Areas. In MMMPA Supervisory Board (Ed.) Monitoring Mediterranean Marine 699 Protected Areas: A set of guidelines to support the development of management plans. 700 Deliverable of the MMMPA European project (FP7-PEOPLE-2011-ITN g.a. no.: 290056) 701 (pp. 27-37), Ancona: Reef Check Italia onlus.

702 Marliave, J. B., Conway, K. W., Gibbs, D. M., Lamb, A., Gibbs, C. (2009). Biodiversity and 703 rockfish recruitment in sponge gardens and bioherms of southern British Columbia, 704 Canada. Marine Biology, 156, 2247-2254.

705 Martin, Y., Bonnefort, J. L., Chancerelle, L. (2002). Gorgonians mass mortality during the 7061999 late summer in french Mediterranean coastal waters: The bacterial hypothesis. Water $707 \quad$ Research, 36, 779-782.

708 Mateos-Molina, D., Palma, M., Ruiz-Valentín, I., Panagos, P., García-Charton, J. A., Ponti, 709 M. (2015). Assessing consequences of land cover changes on sediment deliveries to 710 coastal waters at regional level over the last two decades in the northwestern 711 Mediterranean Sea. Ocean \& Coastal Management, 116, 435-442.

712 McArdle, B. H., Anderson, M. J. (2001). Fitting multivariate models to community data: a 713 comment on distance-based redundancy analysis. Ecology, 82, 290-297. 
714 Mistri, M., Ceccherelli, V. U. (1994). Growth and secondary production of the Mediterranean gorgonian Paramuricea clavata. Marine Ecology-Progress Series, 103, 291-296.

Mistri, M., Ceccherelli, V. U. (1996a). Effects of a mucilage event on the Mediterranean gorgonian Paramuricea clavata. 1. Short term impacts at the population and colony levels. Italian Journal of Zoology, 63, 221-230.

Mistri, M., Ceccherelli, V. U. (1996b). Effects of a mucilage event on the Mediterranean gorgonian Paramuricea clavata. 2. Population recovery after two years. Italian Journal of

Mokhtar-Jamai, K., Pascual, M., Ledoux, J. B., Coma, R., Feral, J. P., Garrabou, J., Aurelle, D. (2011). From global to local genetic structuring in the red gorgonian Paramuricea clavata: The interplay between oceanographic conditions and limited larval dispersal. Molecular Ecology, 20, 3291-3305.

Montero-Serra, I., Garrabou, J., Doak, D. F., Figuerola, L., Hereu, B., Ledoux, J.-B., Linares, C. (2018). Accounting for life-history strategies and timescales in marine restoration. Conservation Letters, 11, e12341-n/a.

Musard, O., Le Dû-Blayo, L., Francour, P., Beurier, J.-P., Feunteun, E., Talassinos, L. (2014).

732 Occhipinti-Ambrogi, A. (2007). Global change and marine communities: Alien species and climate change. Marine Pollution Bulletin, 55, 342-352.

Perez-Portela, R., Cerro-Galvez, E., Taboada, S., Tidu, C., Campillo-Campbell, C., Mora, J., 735 Riesgo, A. (2016). Lonely populations in the deep: Genetic structure of red gorgonians at the heads of submarine canyons in the north-western Mediterranean Sea. Coral Reefs, 35, 1013-1026. 
Piazzi, L., Balata, D., Bulleri, F., Gennaro, P., Ceccherelli, G. (2016). The invasion of

739 Caulerpa cylindracea in the Mediterranean: The known, the unknown and the knowable.

$740 \quad$ Marine Biology, 163

741 Piazzi, L., Balata, D., Cinelli, F. (2007). Invasions of alien macroalgae in Mediterranean

742 coralligenous assemblages. Cryptogamie Algologie, 28, 289-301.

743 Piazzi, L., Gennaro, P., Balata, D. (2012). Threats to macroalgal coralligenous assemblages in 744 the Mediterranean Sea. Marine Pollution Bulletin, 64, 2623-2629.

745 Pilczynska, J., Cocito, S., Boavida, J., Serrao, E., Queiroga, H. (2016). Genetic diversity and 746 local connectivity in the Mediterranean red gorgonian coral after mass mortality events. $747 \quad$ PLOS ONE, 11

748 Ponti, M., Fava, F., Abbiati, M. (2011). Spatial-temporal variability of epibenthic 749 assemblages on subtidal biogenic reefs in the northern Adriatic Sea. Marine Biology, 158, $750 \quad 1447-1459$.

751 Ponti, M., Grech, D., Mori, M., Perlini, R. A., Ventra, V., Panzalis, P. A., Cerrano, C. (2016). 752 The role of gorgonians on the diversity of vagile benthic fauna in Mediterranean rocky 753 habitats. Marine Biology, 163, 1-14.

754 Ponti, M., Perlini, R. A., Ventra, V., Grech, D., Abbiati, M., Cerrano, C. (2014). Ecological 755 shifts in Mediterranean coralligenous assemblages related to gorgonian forest loss. PLoS $756 \quad O N E, 9, \mathrm{e} 102782$.

757 Previati, M., Magliozzi, C., Palma, M., Navone, A., Pantaleo, U., Landi, G., Cerrano, C. 758 (2011). Pruning techniques testing on Paramuricea clavata population affected by mass 759 mortality. Biologia Marina Mediterranea, 18, 40-43.

760 Previati, M., Scinto, A., Cerrano, C., Osinga, R. (2010). Oxygen consumption in 761 Mediterranean octocorals under different temperatures. Journal of Experimental Marine $762 \quad$ Biology and Ecology, 390, 39-48. 
R Core Team. 2017. R: A language and environment for statistical computing. http://www.Rproject.org/

Ribes, M., Coma, R., Gili, J. M. (1999). Heterogeneous feeding in benthic suspension feeders: The natural diet and grazing rate of the temperate gorgonian Paramuricea clavata (Cnidaria: Octocorallia) over a year cycle. Marine Ecology Progress Series, 183, 125-137.

Rinaldi, A., Vollenweider, R. A., Montanari, G., Ferrari, C. R., Ghetti, A. (1995). Mucilages in Italian seas: The Adriatic and Tyrrhenian Seas, 1988-1991. Science of the Total Environment, 165, 165-183.

Rinkevich, B. (2005). Conservation of coral reefs through active restoration measures: Recent approaches and last decade progress. Environmental Science \& Technology, 39, 43334342.

Rivetti, I., Fraschetti, S., Lionello, P., Zambianchi, E., Boero, F. (2014). Global warming and mass mortalities of benthic invertebrates in the Mediterranean Sea. PLoS ONE, 9, e115655.

Rodgers, K. L., Shears, N. T. (2016). Modelling kelp forest primary production using in situ photosynthesis, biomass and light measurements. Marine Ecology Progress Series, 553, 67-79.

Rodriguez, A. D. (1995). The natural products chemistry of West Indian gorgonian octocorals. Tetrahedron, 51, 4571-4618.

Romero, G. Q., Gonçalves-Souza, T., Vieira, C., Koricheva, J. (2015). Ecosystem engineering effects on species diversity across ecosystems: A meta-analysis. Biological Reviews, 90, 877-890.

Rossi, S., Bramanti, L., Broglio, E., Gili, J. M. (2012). Trophic impact of long-lived species indicated by population dynamics in the short-lived hydrozoan Eudendrium racemosum. Marine Ecology Progress Series, 467, 97-111. 
Rossi, S., Bramanti, L., Gori, A., Orejas Saco del Valle, C. (2017). Marine animal forests. The ecology of benthic biodiversity hotspots. Springer International Publishing.

Sánchez-Tocino, L., De La Linde Rubio, A., Lizana Rosas, M. S., Pérez Guerra, T., Tierno

Sandrini-Neto, L., Camargo, M. G. 2012. GAD: An R package for ANOVA designs from population in the Chafarinas Islands? 2018, $18,7$. general principles. https://CRAN.R-project.org/package=GAD

Santangelo, G., Cupido, R., Cocito, S., Bramanti, L., Priori, C., Erra, F., Iannelli, M. (2015). Effects of increased mortality on gorgonian corals (Cnidaria, Octocorallia): Different demographic features may lead affected populations to unexpected recovery and new equilibrium points. Hydrobiologia, 759, 171-187.

Sartoni, G., Urbani, R., Sist, P., Berto, D., Nuccio, C., Giani, M. (2008). Benthic mucilaginous aggregates in the Mediterranean Sea: Origin, chemical composition and polysaccharide characterization. Marine Chemistry, 111, 184-198.

Schiaparelli, S., Castellano, M., Povero, P., Sartoni, G., Cattaneo-Vietti, R. (2007). A benthic mucilage event in North-Western Mediterranean Sea and its possible relationships with the summer 2003 European heatwave: Short term effects on littoral rocky assemblages. Marine Ecology-an Evolutionary Perspective, 28, 341-353.

Sini, M., Kipson, S., Linares, C., Koutsoubas, D., Garrabou, J. (2015). The yellow gorgonian Eunicella cavolini: Demography and disturbance levels across the Mediterranean Sea.

810 Steneck, R. S., Graham, M. H., Bourque, B. J., Corbett, D., Erlandson, J. M., Estes, J. A., 811 Tegner, M. J. (2002). Kelp forest ecosystems: Biodiversity, stability, resilience and future. Environmental Conservation, 29, 436-459. 
813 Streftaris, N., Zenetos, A. (2006). Alien marine species in the Mediterranean - the 100 'worst

814 invasives' and their impact. Mediterranean Marine Science, 7, 87-117.

815 Teixido, N., Albajes-Eizagirre, A., Bolbo, D., Le Hir, E., Demestre, M., Garrabou, J., ...

816 Soria-Frisch, A. (2011). Hierarchical segmentation-based software for cover classification

817 analyses of seabed images (Seascape). Marine Ecology-Progress Series, 431, 45-53.

818 Teixido, N., Casas, E., Cebrian, E., Linares, C., Garrabou, J. (2013). Impacts on coralligenous

819 outcrop biodiversity of a dramatic coastal storm. PLoS ONE, 8

820 Teixido, N., Garrabou, J., Harmelin, J.-G. (2011). Low dynamics, high longevity and

821 persistence of sessile structural species dwelling on Mediterranean coralligenous outcrops.

$822 \quad P L O S O N E, 6$, e23744.

823 Trygonis, V., Sini, M. (2012). photoQuad: A dedicated seabed image processing software,

824 and a comparative error analysis of four photoquadrat methods. Journal of Experimental

$825 \quad$ Marine Biology and Ecology, 424-425, 99-108.

826 Tsounis, G., Martinez, L., Bramanti, L., Viladrich, N., Gili, J.-M., Martinez, A., Rossi, S.

827 (2012). Anthropogenic effects on reproductive effort and allocation of energy reserves in

828 the Mediterranean octocoral Paramuricea clavata. Marine Ecology Progress Series, 449,

$829 \quad$ 161-U193.

830 Underwood, A. J. (1997). Experiments in ecology. Cambridge: Cambridge University Press.

831 Valisano, L., Notari, F., Mori, M., Cerrano, C. (2016). Temporal variability of sedimentation

832 rates and mobile fauna inside and outside a gorgonian garden. Marine Ecology-an

833 Evolutionary Perspective, 37, 1303-1314.

834 Vezzulli, L., Pezzati, E., Huete-Stauffer, C., Pruzzo, C., Cerrano, C. (2013). 16SrDNA

835 pyrosequencing of the Mediterranean gorgonian Paramuricea clavata reveals a link

836 among alterations in bacterial holobiont members, anthropogenic influence and disease

837 outbreaks. PLoS ONE, 8, e67745. 
838 Vidondo, B., Duarte, C. M. (1995). Seasonal growth of Codium bursa, a slow-growing

839 Mediterranean macroalga: In-situ experimental-evidence of nutrient limitation. Marine

$840 \quad$ Ecology Progress Series, 123, 185-191.

841 Wright, S. J. (2002). Plant diversity in tropical forests: A review of mechanisms of species

$842 \quad$ coexistence. Oecologia, 130, 1-14.

843 Young, C. N., Schopmeyer, S. A., Lirman, D. (2012). A review of reef restoration and coral

844 propagation using the threatened genus Acropora in the Caribbean and Western Atlantic.

845 Bulletin of Marine Science, 88, 1075-1098.

846

847 
848 TABLE 1 PERMANOVA test on differences of epibenthic assemblage structures between

849 inside and outside gorgonian forest (Go: 2 levels, fixed), among sites (Si: 9 levels, random),

850 their interaction $(\mathrm{Go} \times \mathrm{Si})$ and among areas within this interaction (Area $(\mathrm{Go} \times \mathrm{Si}))($ square

851 root-transformed percentage cover data, Bray-Curtis coefficient). Estimated component of

852 variation, in percentage of the total (CV\%), was reported for each term of the model.

\begin{tabular}{|c|c|c|c|c|c|c|c|}
\hline \multirow[b]{2}{*}{ Source } & \multirow[b]{2}{*}{ df } & \multirow[b]{2}{*}{ SS } & \multirow[b]{2}{*}{ MS } & \multirow[b]{2}{*}{ Pseudo-F } & \multicolumn{3}{|c|}{ Unique } \\
\hline & & & & & $p$ & perms & CV\% \\
\hline Gorgonian forest (Go) & 1 & 22,252 & $22,252.00$ & 2.61 & 0.0280 & 9944 & 9.4 \\
\hline Site $(\mathrm{Si})$ & 8 & 235,020 & $29,378.00$ & 12.89 & 0.0001 & 9856 & 28.1 \\
\hline $\mathrm{Go} \times \mathrm{Si}$ & 8 & 68,109 & $8,513.60$ & 3.74 & 0.0001 & 9823 & 19.0 \\
\hline Area $(\mathrm{Si} \times \mathrm{Go})$ & 54 & 123,080 & $2,279.20$ & 3.76 & 0.0001 & 9539 & 19.7 \\
\hline Residual & 216 & 130,930 & 606.16 & & & & 23.7 \\
\hline Total & 287 & 579,390 & & & & & \\
\hline
\end{tabular}

853

854 
TABLE 2 Summary of ANOVA tests. Data transformation: sqrt = square root; frt = four root. Degrees of freedom of numerator and denominator are given in parentheses. Significant levels were indicated by the following symbols: $\mathrm{ns}=$ not significant; $*=p<0.05 ; * *=p<0.01 ; * * *=p<0.001$.

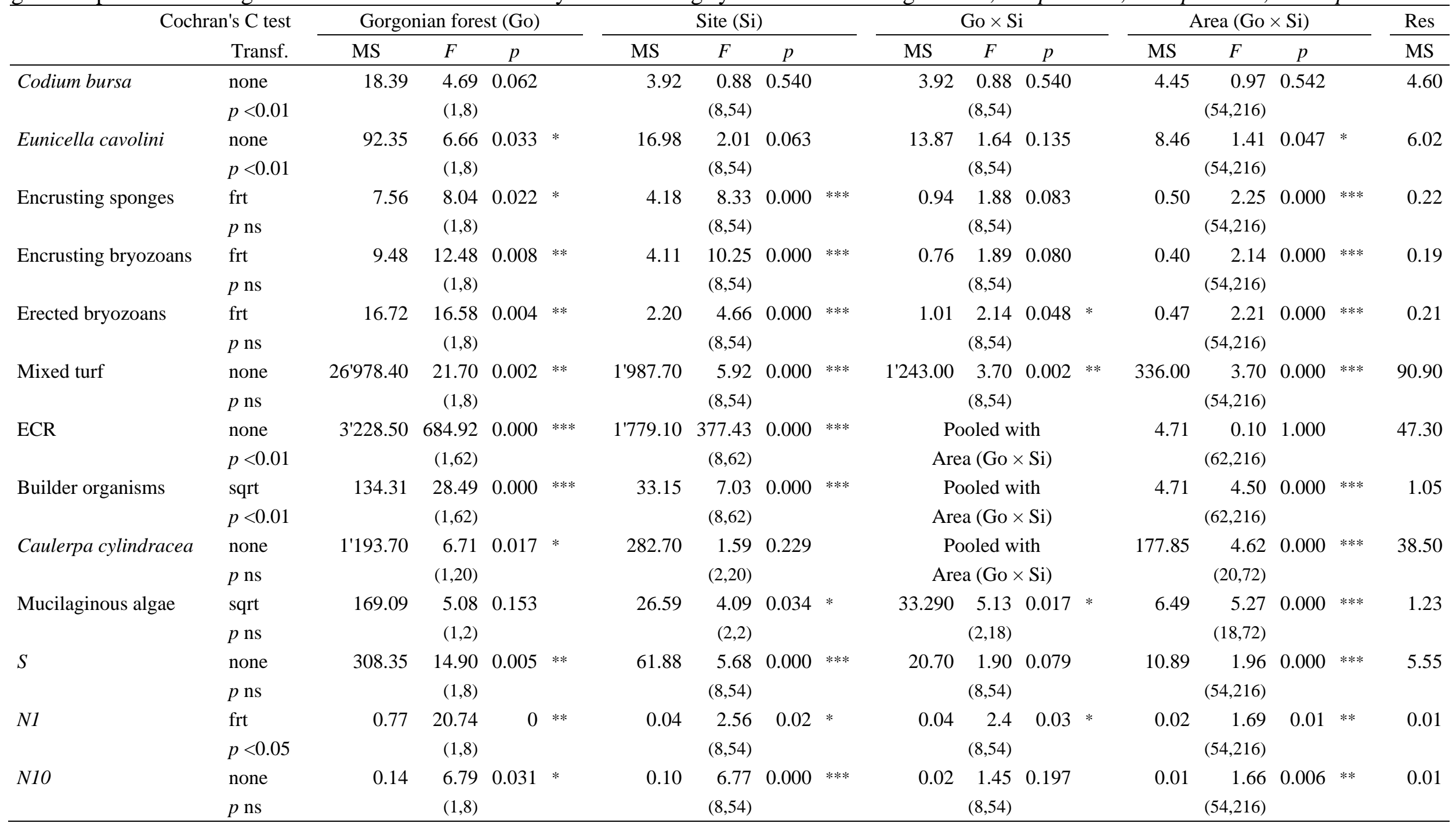




\section{Figures legends}

859

860 FIGURE 1 Study area and study sites (circles): 1, P.te Causinière; 2, Colombara; 3, Punta

861 delle Cannelle; 4, Capo Calvo; 5, Picchi di Pablo; 6, Scoglio del Remaiolo; 7, Punta San

862 Paolo; 8, Zverinac Južni Rt; 9, Rivanjski Kanal (Mercator Projection, Datum WGS 84).

863

864 FIGURE 2 Photographic sampling method (a, courtesy of Adelmo Sorci); a sampled area 865 inside a gorgonian forest at Punta San Paolo, Ustica Island (b); benthic assemblages at 866 Rivanjski Kanal, northern Adriatic (c); a dense gorgonian forest in the Tyrrhenian Sea (d);

867 some thalli of Caulerpa cylindracea at the basis of Paramuricea clavata at Punta delle 868 Cannelle, Elba Island (e); mucilaginous aggregates entrapped by gorgonian branches (f).

869

870 FIGURE 3 Mean ( \pm s.e.) height (a) and percentage cover (b) of Paramuricea clavata inside 871 the gorgonian forest at each study site.

872

873 FIGURE 4 Unconstrained (a; PCoA) and constrained (b; CAP) ordination plots of benthic 874 assemblage data from inside and outside forests of the gorgonian Paramuricea clavata at 9

875 sites in the Mediterranean Sea. Each symbol represents the centroid of 4 areas with 4

876 replicated samples each. Vectors superimposed to plot (a) represent the correlations of

877 substrate inclination, site depth and longitude with the PCoA axes.

878

879 FIGURE 5 Mean ( \pm s.e.) percentage covers of encrusting sponges (a), encrusting bryozoans

880 (b), erect bryozoans (c), mixed turf (d), encrusting calcareous rhodophytes (ECR, e) and all

881 builder organisms together (f), inside and outside forests of the gorgonian Paramuricea

882 clavata at 9 sites in the Mediterranean Sea. Significant levels in SNK tests inside vs. outside 
883 gorgonian forests within sites were indicated by the following symbols: $*=p<0.05 ; * *=p<$

$884 \quad 0.01 ; * * *=p<0.001$.

885

886 FIGURE 6 Polynomial regression fitting (LOESS) between percentage cover of Paramuricea

887 clavata and percentage cover of green algal turf (a) and non-encrusting algae of the genus

888 Peyssonnelia (b). The dashed lines delimit the confidence intervals at $95 \%$.

889

890 FIGURE 7 Mean ( \pm s.e.) percentage covers of Caulerpa cylindracea (a) and mucilaginous

891 aggregates (b), inside and outside forests of the gorgonian Paramuricea clavata at 3 sites in

892 the Mediterranean Sea. Significant levels in SNK tests inside vs. outside gorgonian forests

893 within sites were indicated by the following symbols: $*=p<0.05 ; * *=p<0.01 ; * * *=p<$

8940.001.

895

896 FIGURE 8 Mean ( \pm s.e.) species richness $(S$, a), species diversity in terms of effective

897 number of species $(N 1, \mathrm{~b})$ and the corresponding evenness component $(N 10, \mathrm{c})$, inside and

898 outside forests of the gorgonian Paramuricea clavata at 9 sites in the Mediterranean Sea.

899 